\title{
Mycorrhiza-improved P acquisition of host plants: A mini-review
}

\author{
Guang-Ming Huang ${ }^{1}$, Yong-Jie $\mathrm{Xu}^{2,3,{ }^{*}}$ and Qiang-Sheng $\mathrm{Wu}{ }^{1,}{ }^{*}$ \\ ${ }^{1}$ College of Horticulture and Gardening, Yangtze University, Jingzhou, Hubei 434025, China. \\ ${ }^{2}$ Hubei Key Laboratory of Economic Forest Germplasm Improvement and Resources Comprehensive Utilization, Hubei \\ Collaborative Innovation Center for the Characteristic Resources Exploitation of Dabie Mountains, Huanggang Normal \\ University, Huanggang 438000, China. \\ ${ }^{3}$ Hubei Academy of Forestry, Wuhan, Hubei 430075, China.
}

GSC Biological and Pharmaceutical Sciences, 2021, 14(03), 062-067

Publication history: Received on 03 February 2021; revised on 27 February 2021; accepted on 02 March 2021

Article DOI: https://doi.org/10.30574/gscbps.2021.14.3.0063

\begin{abstract}
As a beneficial endophytic fungus, arbuscular mycorrhizal fungi (AMF) are widely distributed in nature and can symbiotically grow with approx. $80 \%$ of terrestrial plants, helping host plants to grow and develop with increased tolerance to various stresses. One of the most important functions of AMF is to promote the uptake of P from the soil by the host plant. The available findings explain the role of mycorrhizal fungi. For example, AMF increase the phosphorus uptake area of plant roots by improving the root architecture, and the extraradical mycelium can extend beyond the phosphorus-deprived areas that are inaccessible to the root, helping to expand new phosphorus sources. AMF also increase the secretion of phosphatases and organic acids in plant roots to improve the soil environment for accelerating the conversion of insoluble phosphorus. The phosphorus transporter protein genes expression is induced by AMF to enhance host $\mathrm{P}$ acquisition. The review briefly outlines these potential mechanisms and suggests outlooks for future research.
\end{abstract}

Keywords: Acid phosphatase; Mycorrhizal fungi; Low phosphorus; Phosphate transporter

\section{Introduction}

Arbuscular mycorrhizal fungi (AMF) are beneficial fungi in soil that are widely distributed in various ecosystems. After colonizing plant roots, AMF can form a mutual symbiosis with the host root, namely, arbuscular mycorrhiza. In roots, AMF establishs special structures inside and outside the root, such as arbuscules, spores, intraradical mycelium, and extraradical mycelium. These mycorrhizal structures help the root to expand the absorption area of water and mineral nutrients, as well as extend into the soil where the root hairs cannot reach the region to absorb mineral elements. In addition, AMF can colonize neighboring plant roots to form underground common mycelial network. Hence, AMF can promote plant growth, improve root architecture, increase photosynthetic rate and uptake of mineral nutrients, and enhance stress tolerance [1-5].

Low phosphorus stress is one of the major factors limiting agricultural production. In practice, people mainly supplement the phosphorus $(\mathrm{P})$ required by crops by applying $\mathrm{P}$ fertilizers, but plants without low $\mathrm{P}$ stress adaptations difficulty absorb enough $\mathrm{P}$ for normal growth because $80-90 \%$ of $\mathrm{P}$ in arable land is adsorbed by soil particles [6]. In addition, the diffusion coefficient of $\mathrm{P}$ in the soil is small and the uptake of effective soil $\mathrm{P}$ by plants depends largely on the root morphology, such as root surface area, root volume, total root length, and lateral root development at all levels

\footnotetext{
* Corresponding author: Yong-Jie Xu

Hubei Key Laboratory of Economic Forest Germplasm Improvement and Resources Comprehensive Utilization, Hubei Collaborative Innovation Center for the Characteristic Resources Exploitation of Dabie Mountains, Huanggang Normal University, Huanggang 438000, China.
} 
[7]. Under low $\mathrm{P}$ stress, the $\mathrm{P}$ content of plant cells decreases, which is detrimental to photosynthetic phosphorylation and hinders the cycling of NADP+ and NADPH in the Calvin cycle. As a result, low P in plants affects the efficiency of the photosynthetic electron transport chain, which in turn reduces the intensity of various physiological activities of plants [8]. Therefore, it is very urgent to improve the efficiency of plant $\mathrm{P}$ uptake.

It has been shown that AMF promote soil P uptake by host plants, and the positive effect has been widely demonstrated under different crop and environmental conditions [9]. The review simply summarizes the advance in mycorrhizaimproved P acquisition of host plants by means of three potential paths (improved root architecture, released soil phosphatase, and induction of phosphorus transporter protein gene expression).

\section{Improved root architecture by mycorrhization}

$\mathrm{P}$ is easily fixed by the colloids in the soil and difficult to diffuse. Plants rely mainly on the root in the uptake and utilization of $\mathrm{P}$ in the soil, and their root architecture determines the spatial structure of the root system in the soil and the size of the soil contacted area, which is proportional to the efficiency of plant $\mathrm{P}$ uptake [10]. When low $\mathrm{P}$ stress occurs, plants often need to change their root architecture by increasing root length, root: shoot ratio, number of lateral roots, root hair length and density, to increase the area of P uptake by the root system [11-12].

It is assumed that the effect of AMF on plant physiological and biochemical processes is closely related to changes in root architecture, as AMF forms an unique arbuscule structure. The effect of AMF on root architecture is associated with two paths: (1) the root biomass, root surface area, and total root length are increased significantly after AMF inoculation, e.g. Stylosanthes guianensias and Ceratonia siliqua [13-14]; (2) AMF significantly promoted the occurrence of lateral roots and the spatial distribution of roots in the soil. For example, AMF inoculation dramatically elevated the number of lateral roots in grape [15], litchi [16], and rice [17]. In tea, Claroidelglomus etunicatum inoculation significantly increased root-hair length, but not root-hair diameter and density under low soil P levels conditions, indicating the synergistic benefit of AMF and root hairs [18].

The effect of AMF on improving root architecture is more pronounced under stressful environments. For example, Berta et al. [19] found that inoculation of Glomus mosseae BEG12 to tomato infected with Rhizoctonia solani 1556 increased the number of root hairs, which resulted in enhanced P acquisition of the plants. Vallino et al. [20] showed that AMF significantly promoted the increase of root branching in rice under either drought or flooding. Other studies also found that AMF improved plant root architecture under stress conditions such as low temperature, salt stress, and crude oil pollution. [21-23].

\section{Secretion of phosphatase in the soil by mycorrhization}

Most of the $\mathrm{P}$ in the soil are organic, and plants lacking P secrete phosphatases that act on chelates of insoluble P in the soil, activating the conversion of organic P into inorganic P, which can then be absorbed and used. Phosphatase dephosphorylates the corresponding substrates such as phosphates chelated by heavy metal ions (iron and aluminum), completely removing the phosphate group from the substrate molecule by hydrolyzing the phosphate monoester, while generating phosphate ions and free hydroxyl groups [24]. Phosphatases can be classified as acidic, alkaline and neutral phosphatases based on the $\mathrm{pH}$ value. Among them, acid phosphatase is commonly responsive to increased secretion in plants undergoing low P stress. Purple acid phosphatase (PAP) is one of the more specific phosphatases. Plants are induced to express PAPs in large amounts under low P stress and can secrete them into the soil to release soil Pi for plant use [25]. The detection of Arabidopsis revealed that the genes encoding PAPs are AtPAP10, AtPAP12 and AtPAP26, of which AtPAP10 has the strongest ability to hydrolyze insoluble $\mathrm{P}$ and the utilization of insoluble $\mathrm{P}$ by transgenic Arabidopsis was significantly increased when it was overexpressed [26]. Double mutants of AtPAP12 and AtPAP26 represented lower capacity of the hydrolysis of DNA, glucose-6 phosphate, and glycerol triphosphate [27], indicating that the activation and utilization of exogenous organophosphorus involved in different species of PAP may be different. Rubio et al. [28] showed that AMF increased soil acid phosphatase activity under soil contamination. The study by Javot et al. [29] found that AMF-colonized plants promoted an increase in plant phosphatase secretion and thus improved plant P uptake. Our study also revealed that under $0.1 \mathrm{mM}$ and $1 \mathrm{mM}$ P levels, Funneliformis mosseae dramatically reduced leaf PtPAP1 and PtPAP3 and root PtPAP3, but induced the expression of root PtPAP1 in trifoliate orange under $1 \mathrm{mM} P$ levels [30]. This seems to infer that the release of mycorrhizal-induced phosphatase may originate from the mycorrhizal fungus itself rather than from the plant, but more experiments are needed to be done. At the same time, Funneliformis mosseae further stimulated soil acid phosphatase activity of trifoliate orange grown in $0 \mathrm{mM}, 3 \mathrm{mM}$, and $30 \mathrm{mM}$ P levels [31]. However, in tea, Claroideoglomus etunicatum significantly reduced root acid phosphatase activity 
under low P levels conditions, but increased it under optimal P levels [18]. This implies that mycorrhiza-effect changes in plant phosphatase are dependent on soil P levels.

\section{Induction of phosphorus transporter protein gene expression by mycorrhization}

When soil P deficiency occurs, plants increase the synthesis of P transport (PT) proteins. PTs can be classified into low and high affinity systems [32]. Among the PTs, all genes of the Pht1 family belong to the high-affinity system, and this part of genes is mainly responsible for the basic processes of $\mathrm{P}$ uptake and transport in plants [33]. Earlier studies revealed that the genome of rice contained $11 \mathrm{Pht} 1$ family genes based on transcriptional analysis, 10 of which are expressed in the roots [34]. In addition, Mudge et al. [35] analyzed the expression of Pht1;3 and Pht1;4 in Arabidopsis thaliana and found that this class of genes has two functions, namely, promotion of soil P uptake by plants and the translocation of P from the plant to the vascular bundle. Studies on Pht1 genes in tomato and potato showed that among StPT1, StPT2, LePT1 and LePT2, only StPT1 and LePT1 were expressed in large amounts in both P-deficient and non-Pdeficient environments, whereas StPT2 and LePT2 were expressed only in P-deficient environments [36-38].

Is there a link between the ability of mycorrhizae to aid P uptake by host plants and PT proteins? Harrison et al. [39] originally isolated the cellular transmembrane P-running protein gene Gvpt, which has a very similar machinery to the Pth1 family of genes, from Gloumus versiforme. Maldonado et alc40] identified the GipT in Glomus intraradices, which is functionally similar to Gvpt. Hence, it is hypothesized that mycorrhizal roots can improve P nutrition in host plants through two pathways, viz., a high-affinity PTs from the host and AMF [41].

In addition to the $\mathrm{P}$ acquisition by mycorrhizal fungi themselves, the $\mathrm{P}$ transport system of plants is also influenced by AMF. Mycorrhizal roots were found to induce massive expression of StPT3, indicating the specificity of StPT3 induced by mycorrhization [42]. Harrison et al. [43] also isolated a high-affinity PT gene, OsPT11, from alfalfa that was specifically induced by mycorrhizal colonization. Paszkowski et al. [44] obtained the mycorrhiza-induced high-affinity PT protein gene OsOT11 from rice. Grace et al. [45] showed that AMF significantly up-regulated the expression of HvPT8 in the root system. AMF also contain three PT proteins, GvPT, GiPT and GmosPT, and low P promotes the expression levels of these three PTs in mycelium, enhancing the uptake of P from soil by AMF and transporting P to the plant, indirectly improving the $\mathrm{P}$ uptake efficiency of the plant [40]. In addition, Claroideoglomus etunicatum dramatically induced CsPT1 expression but reduced CsPT4 expression in tea plants, irrespective of soil P status, suggesting that CsPT1 is specific for mycorrhization [18]. In trifoliate orange, Funneliformis mosseae inoculation up-regulated the expression of PtaPT3, PtaPT5, and PtaPT6 in roots, regardless of $0.1 \mathrm{mM}$ and $1 \mathrm{mM}$ P levels [30]. AMF up-regulates the expression level of PTs and promotes $\mathrm{P}$ transport in plants [43, 46].

The fact that both mycorrhizal-specific PT genes and other high-affinity PT genes are enhanced in expression in response to low $\mathrm{P}$ stress is well established. StPT3 expression in potato colonized by AMF decreased with increasing soil P levels [41]. Using isotope labeling, mycorrhiza-colonized plants take up $\mathrm{P}$ mainly through mycelium, while $\mathrm{P}$ uptake through root hairs and root surface is almost negligible [47-48]. It is clear that mycorrhizae are essential for upregulating the expression of certain high-affinity PT genes in plants.

\section{Conclusion}

In summary, AMF promote $\mathrm{P}$ uptake in host plants mainly through three paths: (i) improving root architecture to increase soil P uptake area; (ii) promoting the decomposition of organic $\mathrm{P}$ in soil into inorganic P available for plant uptake by increasing the secretion and activity of phosphatase; (iii) up-regulating the expression level of mycorrhizalspecific PT genes to increase the efficiency of P transport in hosts. The three mechanisms described above may occur together on some plants, or one or more may occur on some plants. However, this study also has many urgent prospects, mainly in the following areas:

- How do mycorrhizal fungi regulate root architecture and stimulate lateral root formation? The occurrence of lateral roots depends on various factors, such as nutrient levels, specific genes, etc. The role of mycorrhiza is to be analyzed.

- Numerous studies have shown that mycorrhizal fungi are able to secrete phosphatases into the root zone, but how do mycorrhizal fungi promote phosphatases? Does this phosphatase originate from the plant or AMF?

- Both plants and AMF have a PT system to promote P uptake. Do the two act synergistically or do they compete? Will they be dependent on soil P levels? 


\section{Compliance with ethical standards}

\section{Acknowledgments}

This work was supported by the Local Special Project for Science and Technology Development guided by the central government (2018ZYYD045) and the open fund of Hubei Key Laboratory of Economic Forest Germplasm Improvement and Resources Comprehensive Utilization (202019604).

\section{Disclosure of conflict of interest}

All authors declare that they have no conflict of interest.

\section{References}

[1] Krishna H, Singh SK, Sharma RR, Khawale RN, Grover M, Patel VB. Biochemical changes in micropropagated grape (Vitis vinifera L.) plantlets due to arbuscular mycorrhizal fungi (AMF) inoculation during ex vitro acclimatization. Scientia Horticulturae. 2005; 106: 554-567.

[2] Wu QS, Srivastava AK, Zou YN. AMF-induced tolerance to drought stress in citrus: A review. Scientia Horticulturae. 2013; 164: 77-87.

[3] Larimer AL, Clay K, Bever JD. Synergism and context dependency of interactions between arbuscular mycorrhizal fungi and rhizobia with a prairie legume. Ecology. 2016; 95: 1045-1054.

[4] Mathur S, Sharma MP, Jajoo A. Improved photosynthetic efficacy of maize (Zea mays L.) plants with arbuscular mycorrhizal fungi (AMF) under high temperature stress. Journal of photochemistry and photobiology. B, Biology. 2018; 180: 149-154.

[5] Debeljak M, Elteren V, Johannes T, Špruk A, Izmer A, Vanhaecke F, Vogel-Mikuš K. The role of arbuscular mycorrhiza in mercury and mineral nutrient uptake in maize. Chemosphere. 2018; 212: 1076-1084.

[6] Gerke J, Römer W, Jungk A. The excretion of citric and malic acid by proteoid roots of Lupinus albus L.; effects on soil solution concentrations of phosphate, iron, and aluminum in the proteoid rhizosphere in samples of an oxisol and a luvisol. Zeitschrift für Pflanzenernhrung und Bodenkunde. 1994; 157: 289-294.

[7] Gardner WK, Barber DA. The acquisition of phosphorus by Lupinus albus L.: III. The probable mechanism by which phosphorus movement in the soil/ root interface is enhanced. Plant and Soil. 1983; 70: 107-124.

[8] Jacob J, Lawlor DW. In vivo photosynthetic electron transport does not limit photosynthetic capacity in phosphate-deficient sunflower and maize leaves. Plant, Cell and Environment. 1993; 16: 785-795.

[9] Smith FA, Jakobsen I, Smith SE. Spatial differences in acquisition of soil phosphate between two arbuscular mycorrhizal fungi in symbiosis with Medicago truncatula. New Phytologist. 2000; 147: 357-366.

[10] Vance CP, Uhde SC, Allan DL. Phosphorus acquisition and use: critical adaptations by plants for securing a nonrenewable resource. New Phytologist. 2003; 157: 423-447.

[11] Lopez BJ. The role of nutrient availability in regulating root architecture. Current Opinion in Plant Biology. 2003; 6(3): 280-287.

[12] Gahoonia TS, Nielsen NE. Root traits as tools for creating phosphorus efficient crop varieties. Plant and Soil. 2004; 260: 47-57.

[13] Yao Q, Zhu HH, Chen JZ, Christie P. Influence of an arbuscular mycorrhizal fungus on competition for phosphorus between sweet orange and a leguminous herb. Journal of Plant Nutrition. 2005; 28: 2179-2192.

[14] Cruz C, Green JJ, Watson CA, Wilson F, Martins-Loução MA. Functional aspects of root architecture and mycorrhizal inoculation with respect to nutrient uptake capacity. Mycorrhiza. 2004; 14: 177-184.

[15] Schellenbaum L, Berta G, Ravolanirina F, Tisserant B, Gianinazzi S, Fitter AH. Influence of endomycorrhizal infection on root morphology in a micropropagated woody plant species (Vitis vinifera L.). Annals of Botany. 1991; 68: 135-141.

[16] Padilla IMG, Encina CL. Changes in root morphology accompanying mycorrhizal alleviation of phosphorus deficiency in micropropagated Annona cherimola Mill. plants. Scientia Horticulturae. 2005; 106: 360-369. 
[17] Gutjahr C, Casieri L, Paszkowski U. Glomus intraradices induces changes in root system architecture of rice independently of common symbiosis signaling. New Phytologist. 2009; 182: 829-837.

[18] Shao YD, Hu XC, Wu QS, Yang TY, Srivastava AK, Zhang DJ, Gao XB, Kuča K. Mycorrhizas promote P acquisition of tea plants through changes in root morphology and $\mathrm{P}$ transporter gene expression. South African Journal of Botany. 2021; 137: 455-462.

[19] Berta G, Sampo S, Gamalero E, Massa N, Lemanceau P. Suppression of Rhizoctonia root-rot of tomato by Glomus mosseae BEG12 and Pseudomonas fluorescens A6RI is associated with their effect on the pathogen growth and on the root morphogenesis. European Journal of Plant Pathology. 2005; 111: 279-288.

[20] Vallino M, Fiorilli V, Bonfante P. Rice flooding negatively impacts root branching and arbuscular mycorrhizal colonization, but not fungal viability. Plant, Cell and Environment. 2014; 37: 557-572.

[21] Wu QS, Zou YN, He XH. Contributions of arbuscular mycorrhizal fungi to growth, photosynthesis, root morphology and ionic balance of citrus seedlings under salt stress. Acta Physiologiae Plantarum. 2010a; 32: 297304.

[22] Wu QS, Zou YN. Beneficial roles of arbuscular mycorrhizas in citrus seedlings at temperature stress. Scientia Horticulturae. 2010b; 125: 289-293.

[23] Langer I, Syafruddin S, Steinkellner S, Puschenreiter M, Wenzel WW. Plant growth and root morphology of phaseolus vulgaris L. grown in a split-root system is affected by heterogeneity of crude oil pollution and mycorrhizal colonization. Plant and Soil. 2010; 332: 339-355.

[24] Lü J, Gao XR, Dong ZM, Yi J, An L. Improved phosphorus acquisition by tobacco through transgenic expression of mitochondrial malate dehydrogenase from Penicillium oxalicum. Plant Cell Reports. 2012; 31: 49-56.

[25] Bozzo GG, Raghothama KG, Plaxton WC. Purification and characterization of two secreted purple acid phosphatase isozymes from phosphate-starved tomato (Lycopersicon esculentum) cell cultures. European Journal of Biochemistry. 2010; 269: 6278-6286.

[26] Wang L, Li Z, Qian W, Guo W, Gao X, Huang L, Wang H, Zhu H, Wu JW, Wang D. The Arabidopsis purple acid phosphatase AtPAP10 is predominantly associated with the root surface and plays an important role in plant tolerance to phosphate limitation. Plant Physiology. 2011; 157: 1283-1299.

[27] Robinson WD, Park J, Tran HT, Vecchio1 HAD, Ying S, Zins J, Patel K, McKnigh T, Plaxton W. The secreted purple acid phosphatase isozymes AtPAP12 and AtPAP26 play a pivotal role in extracellular phosphate scavenging by Arabidopsis thaliana. Journal of Experimental Botany. 2012; 63: 6531-6542.

[28] Rubio R, Moraga E, Borie F. Acid phosphatase activity and vesicular-arbuscular mycorhizal infection associated with roots of four wheat cultivars. Journal of Plant Nutrition. 1990; 13: 585-598.

[29] Javot H, Pumplin N, Harrison MJ. Phosphate in the arbuscular mycorrhizal symbiosis: transport properties and regulatory roles. Plant Cell and Environment. 2007; 30: 310-322.

[30] Liu CY, Wu QS, Zou YN. Effect of arbuscular mycorrhizal fungi on phosphorous uptake and phosphatase release in trifoliate orange seedlings. Mycosystema. 2017; 36: 942-949.

[31] Wu QS, Li Y, Zou YN, He XH. Arbuscular mycorrhiza mediates glomalin-related soil protein production and soil enzyme activities in the rhizosphere of trifoliate orange grown under different P levels. Mycorrhiza. 2015; 25: 121-130.

[32] Muchhal US, Pardo JM, Raghothama KG. Phosphate transporters from the higher plant Arabidopsis thaliana. Proceedings of the National Academy of Sciences. 1996; 93: 10519-10523.

[33] Raghothama KG. Phosphate transport and signaling. Current Opinion in Plant Biology. 2000; 3: $182-187$.

[34] Rae AL, Cybinski DH, Jarmey JM, Smith FW. Characterization of two phosphate transporters from barley; evidence for diverse function and kinetic properties amongst members of the Pht1 family. Plant Molecular Biology. 2003; 53: 27-36.

[35] Mudge SR, Rae AL, Diatloff E. Expression analysis suggests novel roles for members of the Pht1 family of phosphate transporters in Arabidopsis. The Plant Journal. 2002; 31: 341-353.

[36] Leggewie G, Willmitzer L, Riesmeier JW. Two cDNAs from potato are able to complement a phosphate uptakedeficient yeast mutant: Identification phosphate transporters from higher plants. The Plant Cell. 1997; 9: 381392. 
[37] Liu CM, Muchhal US, Uthappa M. Tomato phosphate transporter genes are differentially regulated in plant tissues by phosphorus. Plant Physiology. 1998; 116: 91-99.

[38] Gordon-Weeks R, Tong YP, Davies TGE, Leggewie G. Restricted spatial expression of a high affinity phosphate transporter in potato roots. Journal of Cell Science. 2003; 116: 3135-3144.

[39] Harrison MJ, Buuren ML. A phosphate transporter from the mycorrhizal fungus Glomus versiforme. Nature. 1995; 378: 626-632.

[40] Maldonado-Mendoza IE, Dewbre GR, Harrison MJ. A phosphate transporter gene from the extraradical mycelium of an arbuscular mycorrhizal fungus Glomus intraradices is regulated in response to phosphate in the environment. Molecular Plant-Microbe Interactions. 2001; 14: 1140-1148.

[41] Rausch C, Daram P, Brunner S, Jansa J, Laloi M, Leggewie G, Amrhein N, Bucher M. A phosphate transporter expressed in arbuscule containing cells in potato. Nature. 2001; 414: 462-466.

[42] Karandashov V, Bucher M. Symbiotic phosphate transportin arbuscular mycorrhizae. Trends in Plant Science. 2005; 10: 22-29.

[43] Harrison MJ, Dewbre GR, Liu JY. A phosphate transporter from Medicago truncatula involved in the acquisition of phosphate released by Arbuscular mycorrhizal fungi. Plant Cell. 2002; 14: 2413-2429.

[44] Paszkowski U, Kroken S, Roux C Briggs S. Rice phosphate transporters include an evolutionarily divergent gene specifically activated in arbuscule mycorrhizal symbiosis. Proceedings of the National Academy of Sciences of the United States of America. 2002; 99: 13324-13329.

[45] Grace E J, Cotsaftis O, Tester M, Smith FA, Smith SE. Arbuscular mycorrhizal inhibition of growth in barley cannot be attributed to extent of colonization, fungal phosphorus uptake or effects on expression of plant phosphate transporter genes. New Phytologist. 2009; 181: 938-949.

[46] Casieri L, Lahmidi NA, Doidy J, Veneault-Fourrey C, Migeon A, Bonneau L, Courty P, Garcia K, Charbonnier M, Delteil A, Brun A, Zimmermann S, Plassard C, Wipf D. Biotrophic transportome in mutualistic plant-fungal interactions. Mycorrhiza. 2013; 23: 597-625.

[47] Smith SE, Smith FA, Jakobsen I. Mycorrhizal fungi can dominate phosphate supply to plants irrespective of growth responses. Plant Physiology. 2003; 33: 16-20.

[48] Smith SE, Smith FA, Jakobsen I. Functional diversity in arbuscular mycorrhizal (AM) symbioses: The contribution of the mycorrhizal P uptake pathway is not correlated with mycorrhizal responses in growth or total P uptake. New Phytologist. 2004; 162: 511-524. 